\title{
Ampelographic description, ampelometric screening and agrobiological characteristics of the Donus grape variety
}

\author{
Alexander Maistrenko ${ }^{1, *}$, Lyudmila Maistrenko ${ }^{1}$, Nadezhda Duran $^{1}$, and Natalia Matveeva ${ }^{1}$ \\ ${ }^{1}$ All-Russian Research Ya.I.Potapenko Institute of Viticulturel and Winemaking - Branch of Federal \\ State Budget Scientific Institution "Federal Rostov Agricultural Research Centre", 346421, \\ Baklanovsky av., 166, Novocherkassk, Russia
}

\begin{abstract}
The agrobiological and ampelographic characteristics of the Donus interspecific grape variety are given. A variety of universal use, average ripening period, the duration of the production period for 20102019 was 146 days with the sum of active temperatures 3297 0C. The variety is characterized by high winter hardiness. With a sum negative temperature of $5860 \mathrm{C}$ and an absolute minimum of minus $250 \mathrm{C}$, the live buds from $49 \%$ to $72.8 \%$. Fruit shoots $90-100 \%$, fruitfulness ratio 1.8 . Yield / bush $\geq 6.9 \mathrm{~kg}$ with a planting pattern of $3 \mathrm{~m} \times 1.5 \mathrm{~m}$. It has bisexual flower, clusters of medium density, cylindro-conical with $1-2$ wings, weighing $212 \mathrm{~g}$. The berry is oval, greenish-yellow, weighing about $3 \mathrm{~g}$. The parameters of the berry are $14.6 \times 13.4 \mathrm{~mm}$. The pulp is juicy with muscat aroma. Differs in moderate sugar accumulation with moderate acidity. Resistance to mildew and oidium is high. The variety has been defined as a donor of mildew resistance. It is used for the production of juices, dry and sparkling wines, fresh consumption. The wine degustation evaluation is on average 8.5 points on a ten-point scale. The Donus is a perspective variety for commercial vitiviniculturel.
\end{abstract}

\section{Introduction}

During 2014-2019, there is a 13\% decrease in Russian wine import against the background ofincrease consumption, which indicates the growing demand for Russian wines in the domestic market. According to the Federal Service for the Regulation of the Alcohol Market, in 2019 Russia produced 328 million liters of still wines and 132 million liters of sparkling wines, which is $8 \%$ and 6\% more than in 2018. Production in 2019 increased for the first time in the last 4 years.

It is necessary to use all available opportunities to improve the taste and dietary qualities of wine by reducing the pesticide load of grape plantations and improving production technology. This indicates the need to revise the varietal policy in viticulture, it is necessary to include in planting grape varieties that meet modern technologies using climatic indices of plant adaptation to climatic growing conditions, including taking into account the

\footnotetext{
* Corresponding author: LA-majstrenko@yandex.ru
} 
duration of the frost-free period [1-4]. The northern zone of industrial viticulture in Russia makes special demands on the degree of adaptation of varieties in connection with a shorter growing season, significant winter frosts and provocative thaws that are destructive for grapes, followed by a sharp drop in temperature. Temperature anomalies not only significantly reduce the productivity of grape plantations, but sometimes lead to the complete death of the bushes. Recently, there has been an increase in the frequency of stressful situations due to climate change. In this regard, work on the study of the reaction of varieties in difficult climatic conditions and the accumulation of long-term data on the behavior of varieties in specific regions are relevant $[2,5-6]$.

Insufficiently high frost resistance of varieties is one of the main limiting factors for expanding the area of industrial cultivation of grapes. Improving the assortment on the basis of winter hardiness is an urgent and practically significant task for the northern regions of grape growing. Due to the instability of weather conditions, work on the creation of economically more profitable varieties with genetically determined resistance to low winter temperatures, pests and diseases are very relevant and are being carried out on different scales in almost all specialized institutes of the world. The introduction into production of new highly productive, winter-hardy varieties is of decisive importance in increasing the profitability of grape plantations [7-8].

Traditionally, most of the European grape varieties are cultivated in the world for wine production, which have proven themselves to be of high quality of finished products [9-10]. But work to improve the grape assortment by including resistant varieties of interspecific origin is being carried out in many countries with a developed viticulture industry [7, 1112]. In Russia, in the northern zone of industrial viticulture, the level of frost resistance of the variety is one of the main factors that determine the prospects for its use in production. Therefore, the topic of breeding frost-resistant, high-quality technical varieties meets the requirements of practical significance, novelty and relevance. The domestic grape assortment should contain new varieties that have group resistance to unfavorable environmental conditions, increased resistance to major fungal diseases and a sufficiently high quality of wine products produced from them.

To study the degree of resistance of grape varieties to fungal diseases, it is of interest to work on the correlation

dependence of the morphological traits of leaves and the degree of mildew damage to the leaf apparatus [13]. To calculate the potential yield of a variety, the study of agrobiological indicators remains relevant: the mass of bunch, the coefficient of fruiting, which depend primarily on the genetic potential of the variety [14]. For a complete study of the variety, a combined approach should be used, including phenotypic characteristics (ampelographic description and oenological characteristics) and molecular analysis [15].

Thus, the creation and complete, detailed ampelographic and agrobiological study of grape varieties is relevant and necessary for the admission of a variety to cultivation in a particular region.

\section{Methodology}

The study of agrobiological and phenotypic indicators of the Donus grape variety was carried out on the territory of the Experimental field ARRIV\&W - a branch of the "Federal Rostov Agricultural Research Centre", Novocherkassk, Rostov Region, Russia. Donus variety grafted on Berlandieri $\times$ RipariaKober $5 \mathrm{BB}$ stock. The study was carried out according to generally accepted methods in viticulture.

Phenological observations, determination of indicators of the load of bushes with eyes, shoots and crops, fertility of bushes, weight accounting of the harvest, study of the strength 
of growth and the degree of ripening of annual shoots, the ripening time of berries were carried out according to the method of M.A. Lazarevsky"Study of grape varieties", 1963.

Evaluation of winter hardiness and frost resistance was carried out according to the number of blossoming buds that developed full-fledged shoots on the bushes, the productivity and yield of the bushes.

Evaluation of the quality of the crop is carried out by determining the content of sugars and acids in the juice of berries as they ripen. The sugar content of the juice of berries was determined by a refractometric method, the acidity was titrated with $0.1 \mathrm{~N} \mathrm{NaOHsolution}$ against bromothymol blue.

Description of the variety was carried out according to the international methodology, finalized by the Federal State Budgetary Institution "State Variety Commission", the description methodology developed by M. Lazarevsky.

Ampelometric screening was carried out using the program: Analyzer of morphology and structure of plants "SIAMS Mesoplant" [25].

The wine is prepared in the laboratory of the Institute's wine-making technology. After self-clarification and removal of wines from the sediment, their analytical and organoleptic studies were carried out. The technological assessment was carried out in accordance with the current regulatory instructions, the sugar content of the wort and the content of titratable acids were determined according to the State Standard.

The analysis of the chemical composition of wine was carried out using methods of analysis generally accepted in winemaking.

The organoleptic assessment was carried out by the institute's tasting committee on a 10 -point scale.

\section{Research results}

The Donus variety (patent No. 10257 dated 06/05/2019) was bred to All-Russian Research Ya.I. Potapenko Institute of Viticulturel and Winemaking - Branch of Federal State Budget Scientific Institution "Federal Rostov Agricultural Research Centre as a result of crossing the SV 12-375 and Druzhba varieties.Included in the State Register of Breeding Achievements Permitted for Use in 2020.

Refers to varieties of universal use, the average ripening period, the duration of the production period varies from year to year: from 131 to 164 days, the average for the 10 studied years is 146 days, the sum of active temperatures until the full ripeness of the berries was $3297^{\circ} \mathrm{C}$. In Novocherkassk, it ripens in mid or late September (table 1).

Table 1.The stages of the vegetation grapes variety Donusin 2010-2019

\begin{tabular}{|l|l|l|l|l|l|l|}
\hline \multirow{2}{*}{ Years } & \multicolumn{3}{|l|}{ The stages of the vegetation } & \multicolumn{2}{l|}{ Production period } \\
\cline { 2 - 6 } & $\begin{array}{l}\text { beginning of } \\
\text { bud opening }\end{array}$ & $\begin{array}{l}\text { beginning of } \\
\text { flowering }\end{array}$ & $\begin{array}{l}\text { beginning of } \\
\text { berry } \\
\text { ripening }\end{array}$ & $\begin{array}{l}\text { full maturity } \\
\text { of berries } \\
\text { number }\end{array}$ & $\begin{array}{l}\text { of } \\
\text { temperatures, } \\
\mathbf{0}^{\mathbf{C}}\end{array}$ \\
\hline 2019 & 24.04 & 24.05 & 25.07 & 5.09 & 132 & 2934 \\
\hline 2018 & 23.04 & 25.05 & 31.07 & 1.10 & 161 & 3738 \\
\hline 2017 & 28.04 & 9.06 & 30.07 & 10.10 & 165 & 3525 \\
\hline 2016 & 15.04 & 4.06 & 23.07 & 27.09 & 165 & 3463 \\
\hline 2015 & 3.05 & 4.06 & 22.07 & 12.09 & 134 & 3063 \\
\hline 2014 & 25.04 & 30.05 & 18.07 & 3.10 & 161 & 3528 \\
\hline 2013 & 28.04 & 26.05 & 18.07 & 3.09 & 128 & 3049 \\
\hline 2012 & 23.04 & 19.05 & 6.07 & 1.09 & 131 & 3128 \\
\hline 2011 & 4.05 & 6.06 & 27.07 & 28.09 & 147 & 3281 \\
\hline 2010 & 1.05 & 4.06 & 3.08 & 14.09 & 136 & 3263 \\
\hline average & 26.04 & 31.05 & 22.07 & 19.09 & 146 & 3297 \\
\hline
\end{tabular}


Young shoot. The crown of a young shoot is open, bronze with a slight tomentose pubescence. The first leaf above is shiny, bronze in color, the main veins are green, below the leaf is green with a slight tomentose pubescence. The second leaf from above is green with a bronze tint, from below - green with a weak tomentose pubescence. The edges of the leaves have an anthocyanin coloration (brown-red clear outline). The petiole of a young leaf is green with wine-red stripes (Figure 1). The young shoot is erect, the color of the dorsal side of the internode is green, the ventral side is green with red stripes, the nodes on the dorsal side are wine-red, on the ventral side they are green, the number of tendrils on the shoot is more than three average lengths.

The leaves are pentagonal, of medium size: the area of the leaf blade is on average 195, $9 \mathrm{~cm}^{2}$, the perimeter of the leaf is on average $126.35 \mathrm{~cm}$; leaves are green, moderately dissected, three-lobed, less often five-lobed, the upper side of the leaf is smooth or slightly reticulate-wrinkled, underneath is sparse bristly pubescence. The upper notch is open, lyreshaped with parallel or vaulted sides, the depth of the notches is medium or shallow. The lower notches are small, open in the form of a reentrant angle. The petiolate notch is usually open, vaulted or lyre-shaped with a rounded bottom. The denticles at the ends of the lobes are large, narrowly triangular, with a concave-sided apex extended at the tip. The denticles along the edge of the leaf are large, sharp, saw-shaped with concave or straight sides.

The petiole is wine-red, $8.54 \mathrm{~cm}$ long and shorter than the midrib (figure 1). Autumn color of leaves is yellow.

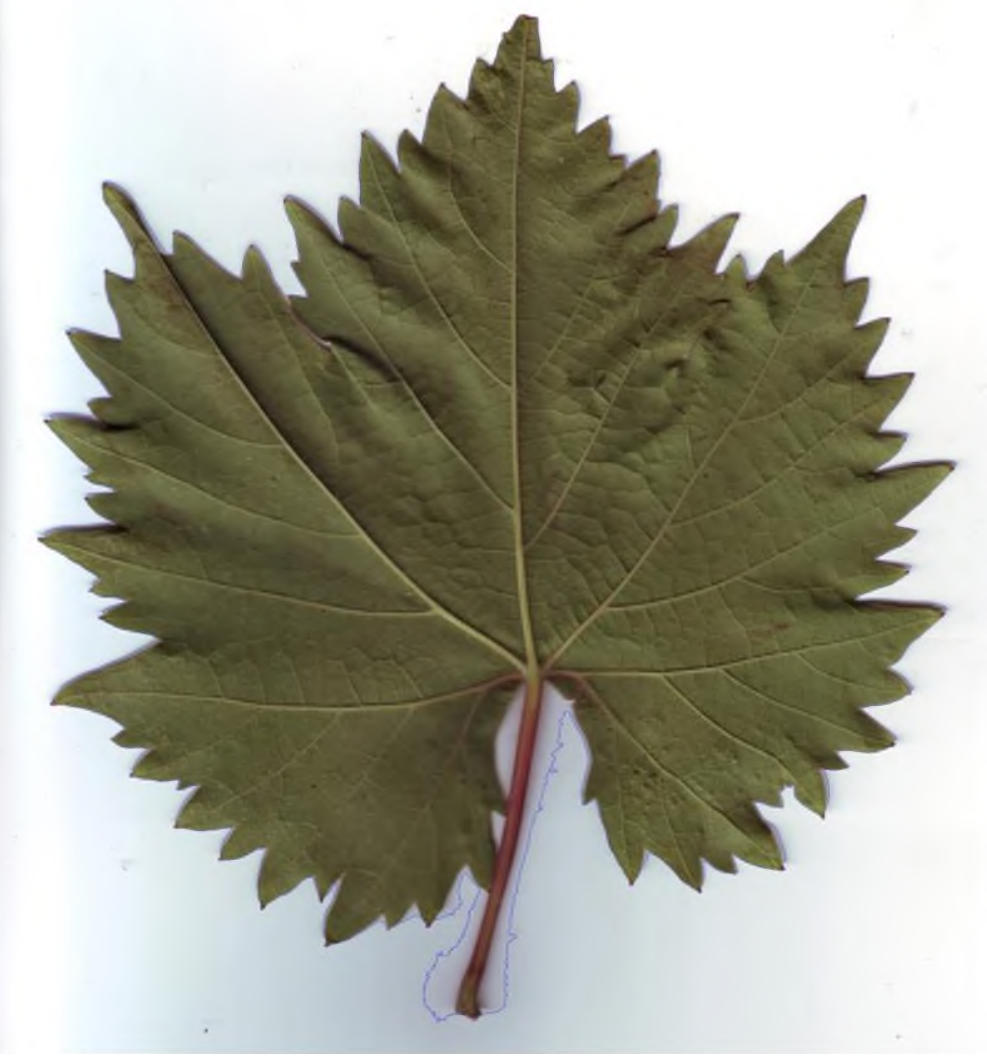

Fig. 1. Leaf of the Donus variety 
For additions to the description of the leaves of the Donusvariety on the distinctness, uniformity and stability, measurements of 15leaves were made using the computer program Analyzer of morphology and structure of plants "SIAMS Mesoplant" for 33 parameters, the average data of measurements are presented in Table 2.

Table 2. Parameters of the leaves of the Donus variety

\begin{tabular}{|c|c|c|c|c|c|}
\hline No. & Measurement parameter & $\begin{array}{c}\text { Unit } \\
\text { measuremen } \\
t\end{array}$ & Maximum & Minimum & Average \\
\hline 1. & Leaf surface area, $\mathrm{S}$ & $\mathrm{cm}^{2}$ & 147.30 & 240.60 & 195.90 \\
\hline 2. & The perimeter of the sheet plate, $\mathrm{P}$ & $\mathrm{cm}$ & 103.10 & 154.90 & 126.35 \\
\hline 3. & Sheet plate length, $\mathrm{N}$ & $\mathrm{cm}$ & 17.23 & 21.70 & 19.26 \\
\hline 4. & Sheet plate width, $\mathrm{W}$ & $\mathrm{cm}$ & 15.84 & 20.10 & 17.90 \\
\hline 5. & Petiole length, L0 & $\mathrm{cm}$ & 6.80 & 10.85 & 8.54 \\
\hline 6. & Midvein, L & $\mathrm{cm}$ & 12.60 & 15.84 & 13.90 \\
\hline 7. & Upper right lateral vein, Lr1 & $\mathrm{cm}$ & 8.15 & 14.38 & 12.20 \\
\hline 8. & Lower right lateral vein, Lr2 & $\mathrm{cm}$ & 7.60 & 11.20 & 9.30 \\
\hline 9. & Upper left lateral vein, L11 & $\mathrm{cm}$ & 11.48 & 13.07 & 12.30 \\
\hline 10. & Lower left lateral vein, L12 & $\mathrm{cm}$ & 7.40 & 10.08 & 9.00 \\
\hline 11. & Angle alpha, $\alpha \wedge$ & degree & 33.40 & 57.10 & 43.60 \\
\hline 12. & Betta angle, $\beta \wedge$ & degree & 34.90 & 58.50 & 48.45 \\
\hline 13. & Zetta angle, $\mathrm{c} \wedge$ & degree & 35.10 & 75.10 & 49.30 \\
\hline 14. & Angle gamma, $\mathrm{t} \wedge$ & degree & 41.10 & 84.50 & 61.42 \\
\hline 15 . & Delta angle, $\mathrm{d} \wedge$ & degree & 102.10 & 139.50 & 119.95 \\
\hline 16. & Upper tooth length, ld1 & $\mathrm{cm}$ & 0.63 & 1.90 & 1.35 \\
\hline 17. & Upper tooth width, ad1 & $\mathrm{cm}$ & 0.68 & 1.63 & 1.076 \\
\hline 18. & Length of the right extreme tooth, ldr2 & $\mathrm{cm}$ & 1.0 & 2.19 & 1.66 \\
\hline 19. & Right extreme tooth width, adr2 & $\mathrm{cm}$ & 0.86 & 1.80 & 1.18 \\
\hline 20. & Length of the left extreme tooth, ld12 & $\mathrm{cm}$ & 1.06 & 1.87 & 1.50 \\
\hline 21. & Left extreme tooth width, ad12 & $\mathrm{cm}$ & 0.94 & 1.57 & 1.21 \\
\hline 22. & Length of the right lower tooth, ldr4 & $\mathrm{cm}$ & 0.85 & 1.58 & 1.14 \\
\hline 23. & Width of the right lower tooth, adr4 & $\mathrm{cm}$ & 0.78 & 1.68 & 1.21 \\
\hline 24. & Length of the lower left tooth, ld14 & $\mathrm{cm}$ & 0.75 & 1.40 & 1.05 \\
\hline 25. & Left lower tooth width, adl4 & $\mathrm{cm}$ & 1.02 & 1.51 & 1.23 \\
\hline 26. & Distance between lower blades, $\mathrm{d}$ & $\mathrm{cm}$ & 1.37 & 7.23 & 3.61 \\
\hline 27. & Depth of petiole notch, h0 & $\mathrm{cm}$ & 2.87 & 5.45 & 4.27 \\
\hline 28. & Top right pre-coil distance, $\mathrm{hr} 1$ & $\mathrm{~cm}$ & 4.30 & 7.61 & 6.20 \\
\hline 29. & Left upper pre-coil distance, hll & $\mathrm{cm}$ & 3.81 & 7.34 & 5.97 \\
\hline 30. & Right bottom pre-coil distance, hr2 & $\mathrm{cm}$ & 4.28 & 8.90 & 6.80 \\
\hline 31. & Left bottom pre-coil distance, h12 & $\mathrm{cm}$ & 4.54 & 8.34 & 6.90 \\
\hline 32. & Lowest right vein, Lr3 & $\mathrm{cm}$ & 2.68 & 6.0 & 3.50 \\
\hline 33. & The lowest left vein, L13 & $\mathrm{cm}$ & 2.20 & 5.60 & 3.40 \\
\hline
\end{tabular}

The flower is bisexual. There are five stamens. The stamenfilaments are longer than the pistil.Bunches of medium density, cylindrol-conical with 1-2 wings, weighing $212 \mathrm{~g}$. The stalk is long, green, sometimes lignified, the stem is green, herbaceous (figure 2).

The berry is oval, greenish-yellow with an intense pruina, weighing about $3 \mathrm{~g}$, the parameters of the berry are $14 / 6 \times 13.4 \mathrm{~mm}$ (figure 3 ). 


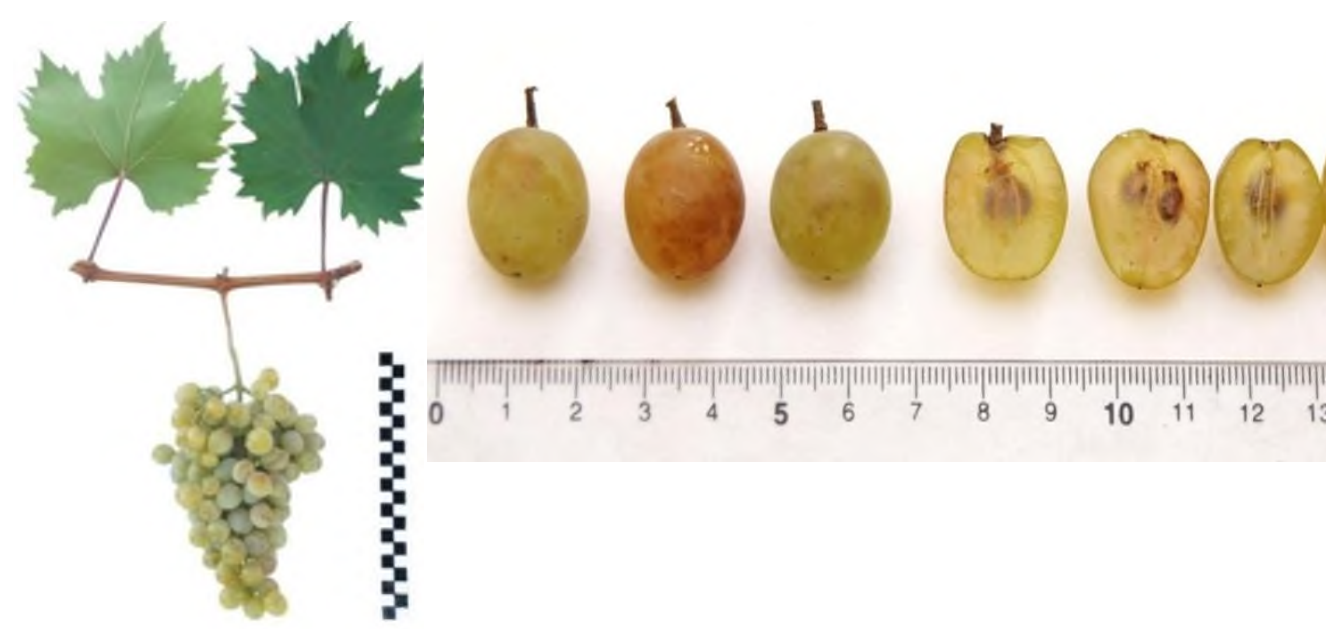

Fig. 2. Ampelographic snapshot of Donus

Fig. 3.Donus grape berries

The pulp is juicy with a muscat aroma. Differs in moderate sugar accumulation -up to $240 \mathrm{~g} / \mathrm{dm}^{3}$, with moderate acidity: 3.6-7.0 $\mathrm{gd} / \mathrm{m}^{3}$ (Table 3).

Bushes are vigorous. The internodes of an annual ripe shoot are light brown, the nodes are brown. The variety is characterized by high winter hardiness, the percentage of budding is from 49 to $100 \%$. Fruiting shoots are $90-100 \%$, the fruitfulness ratio 1.8 . On a singleplane trellis, with a planting pattern of $3 \times 1,5 \mathrm{~m}$. The yield from 1 bush $6.9 \mathrm{~kg}$ and more. The recommended load is $20-25$ buds per bush, pruning of fruiting vines is short 2-3 buds (table 3).

Table 3.Commercially valuable characteristics of the technical grape variety Donus, 2010-2019.

\begin{tabular}{|c|c|c|c|c|c|c|c|c|}
\hline Years & $\begin{array}{c}\text { Normal } \\
\text { shoots } \\
\text { per } \\
\text { bush, } \\
\text { pcs. }\end{array}$ & $\begin{array}{c}\text { Live } \\
\text { buds, \% }\end{array}$ & $\begin{array}{c}\text { Fruit- } \\
\text { bearing } \\
\text { shoots, } \\
\text { \%o }\end{array}$ & $\begin{array}{c}\text { Fruitful } \\
\text {-ness } \\
\text { ratio }\end{array}$ & $\begin{array}{c}\text { Average } \\
\text { bunch } \\
\text { weight, } \\
\text { g }\end{array}$ & $\begin{array}{c}\text { Shootpr } \\
\text { oducti- } \\
\text { vity, g }\end{array}$ & $\begin{array}{c}\text { Bush } \\
\text { yield, } \\
\text { kg }\end{array}$ & $\begin{array}{c}\text { Estimat } \\
\text { ed yield, } \\
\text { c/ha }\end{array}$ \\
\hline 2019 & 20 & 100 & 94.0 & 1.7 & 250 & 425 & 8.5 & 189 \\
\hline 2018 & 25 & 91.2 & 95.0 & 1.6 & 164 & 262 & 6.5 & 144 \\
\hline 2017 & 29 & 89.0 & 98.0 & 1.5 & 190 & 285 & 8.3 & 184 \\
\hline 2016 & 19 & 72.8 & 96.5 & 1.6 & 129 & 206 & 3.9 & 87 \\
\hline 2015 & 13 & 49.0 & 42.1 & 0.5 & 208 & 104 & 1.3 & 29 \\
\hline 2014 & 38 & 83.2 & 79.0 & 1.1 & 137 & 151 & 5.7 & 127 \\
\hline 2013 & 48 & 83.1 & 82.2 & 1.4 & 150 & 210 & 10.1 & 224 \\
\hline 2012 & 23 & 68.2 & 90.1 & 1.5 & 304 & 455 & 10.3 & 229 \\
\hline 2011 & 18 & 78.3 & 93.0 & 1.6 & 342 & 547 & 9.8 & 218 \\
\hline 2010 & 23 & 92.1 & 96.0 & 1.7 & 246 & 418 & 4.4 & 98 \\
\hline avera & 26 & 80.7 & 86.5 & 1.4 & 212 & 306 & 6.9 & 153 \\
ge & & & & & & & & \\
\hline
\end{tabular}

The Donus variety can withstand frost up to $28{ }^{0} \mathrm{C}$ without covering the bushes. Ripening of shoots and regeneration capacity are good. After the winter of 2005-2006 at a minimum air temperature of minus $28{ }^{\circ} \mathrm{C}$, Donus recovered with shoots from old wood, the bush trunk and vine arms had minor damage to the bast. In 2012, with a sum of negative temperatures of $586{ }^{\circ} \mathrm{C}$ and an absolute minimum temperature of minus $24{ }^{0} \mathrm{C}, 68,2 \%$ of 
living buds were noted, in 2015 with an absolute minimum of temperatures of minus $25{ }^{0} \mathrm{C}$ and sharp fluctuations in spring temperatures $-49,0 \%$ of living buds.

In the North Caucasus region of Russia, the most dangerous fungal diseases of grapes are: mildew (PlasmoparaviticolaBerl. Et de Toni), powdery mildew (UncinulanecatorBurril.), Gray rot (Botrytis cinerea Pers.). The maximum infestation of the Donus variety with mildew is 2,5 points, with mildew and gray rot 2,0 points (table 4 ).

Table 4. Resistance to adverse environmental influences, point

\begin{tabular}{|c|c|c|c|c|c|c|}
\hline \multirow[t]{3}{*}{ Years } & \multicolumn{5}{|c|}{ Sustainabilityindicators } & \multirow[t]{3}{*}{ Winterhardines } \\
\hline & \multicolumn{3}{|c|}{ resistance to fungal diseases } & \multicolumn{2}{|c|}{$\begin{array}{c}\text { indicators of } \\
\text { negative }\end{array}$} & \\
\hline & Mildew & Oidium & Gray & $\min$, & sum & \\
\hline 2010 & 0 & 0 & 0 & 22.0 & 418 & 5.0 \\
\hline 2011 & 1.0 & 0.5 & 0 & 20.5 & 450 & 4.0 \\
\hline 2012 & 0 & 0 & 0 & 24.0 & 586 & 4.0 \\
\hline 2013 & 2.0 & 2.0 & 2.0 & 18.5 & 293 & 4.0 \\
\hline 2014 & 1.0 & 1.0 & 0 & 24.6 & 325 & 4.0 \\
\hline 2015 & 2.5 & 2.0 & 0 & 24.5 & 284 & 3.0 \\
\hline 2016 & 2.0 & 2.0 & 0 & 20.5 & 200 & 4.0 \\
\hline 2017 & 1.5 & 1.5 & 0 & 18.9 & 389 & 5.0 \\
\hline 2018 & 1.0 & 1.0 & 0 & 13.6 & 214 & 5.0 \\
\hline 2019 & 1.0 & 2.0 & 0 & 11.5 & 197 & 5.0 \\
\hline average & 1.2 & 1.2 & 0.2 & 19.9 & 366 & 4.3 \\
\hline $\max$ & 2.5 & 2.0 & 2.0 & 24.6 & 586 & 3.0 \\
\hline
\end{tabular}

The variety was determined as a donor of mildew resistance, the maximum damage to the leaves was noted at 2.5 points, and the average damage was 1.2 points. The most epiphytotic year was 2015. This year, the analysis of the hybrid offspring of four crosses: Donus $\times$ Muscat Golodrigi (resistant $\times$ resistant), Donus $\times$ Mugofir (resistant $\times$ tolerant), Donus $\times$ Efremovskii and Pukhliakovskii belyi $\times$ Donus (resistant $\times$ susceptible) showed a high percentage of tolerant seedlings (from 23 to $68 \%$ ) and $8 \%$ resistant seedlings in the population resistant $\times$ resistant. Higher results in the inheritance of mildew resistance by hybrid offspring are shown when using the Donus variety as the maternal form (figure 4, 5).

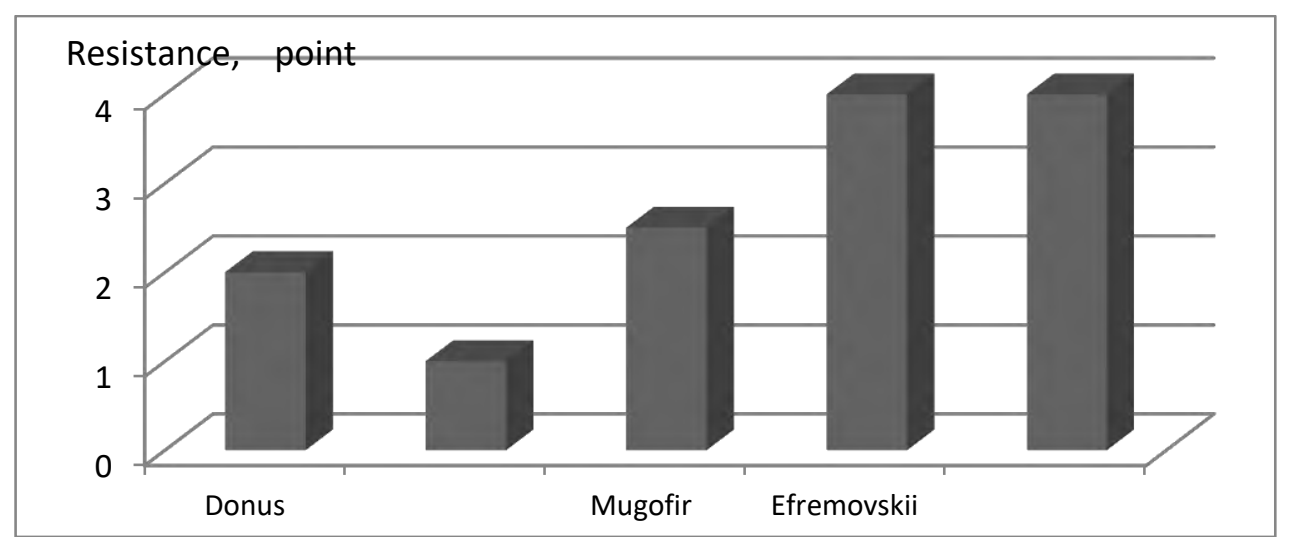

Fig. 4 .Resistance to mildew of parental forms 


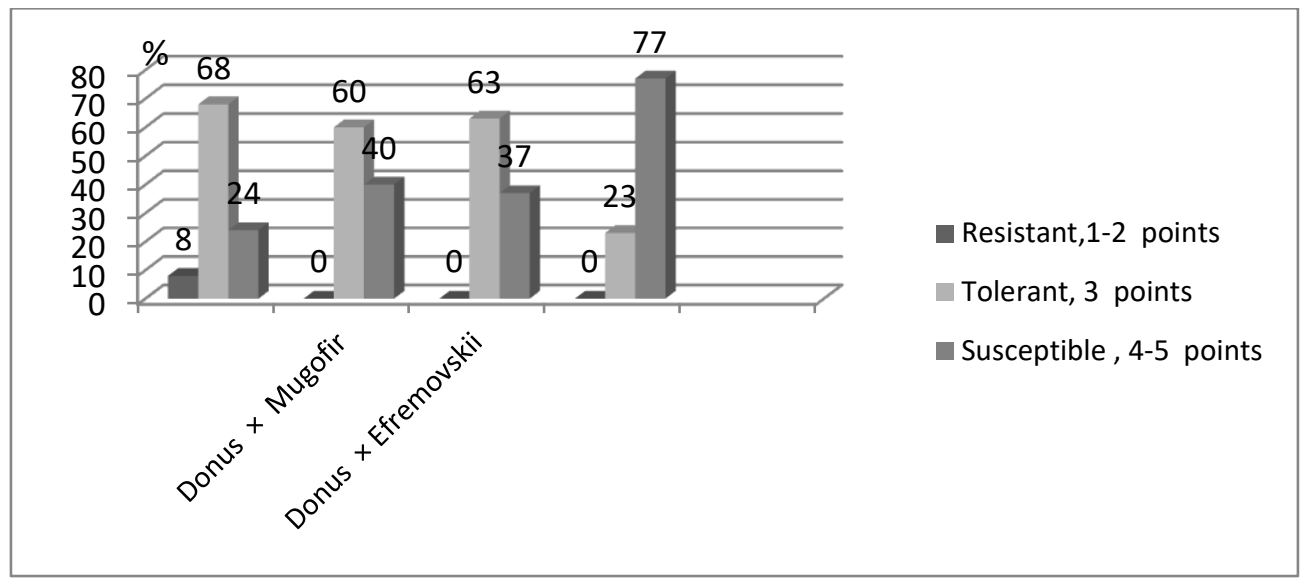

Fig. 5.Distribution of hybrid offspring by points of resistance to mildew, \%.

Donus is characterized by a high juice yield $-79 \%$ on average, which is very valuable for winemaking (table 4).

Table 4. Mechanical composition of bunches and berries of the technical grape variety Donus, 20102019

\begin{tabular}{|c|c|c|c|c|c|c|c|c|c|}
\hline \multirow[t]{2}{*}{ Years } & \multirow{2}{*}{$\begin{array}{c}\text { Date } \\
\text { of } \\
\text { analys } \\
\text { is }\end{array}$} & \multicolumn{2}{|c|}{$\begin{array}{l}\text { Average } \\
\text { weigh, g }\end{array}$} & \multirow[t]{2}{*}{$\begin{array}{l}\text { Stem, } \\
\%\end{array}$} & \multirow[t]{2}{*}{$\begin{array}{l}\text { Skin } \\
\text { with } \\
\text { pulp, } \\
\%\end{array}$} & \multirow[t]{2}{*}{$\begin{array}{c}\text { Seed } \\
\mathbf{s ,} \%\end{array}$} & \multirow{2}{*}{$\begin{array}{c}\text { Juice } \\
\text { yield, } \\
\%\end{array}$} & \multicolumn{2}{|c|}{$\begin{array}{c}\text { Mass } \\
\text { concentratio } \\
\mathbf{n}, \\
\mathbf{g} / \mathbf{d m}^{3}\end{array}$} \\
\hline & & $\begin{array}{c}\text { bun } \\
\text { ch }\end{array}$ & $\begin{array}{c}\text { ber } \\
\text { ri }\end{array}$ & & & & & sugar & $\begin{array}{c}\text { aci } \\
\text { d }\end{array}$ \\
\hline 2019 & 17.09 & 250 & 3.2 & 2.3 & 13.2 & 5.2 & 79.3 & 243 & 3,6 \\
\hline 2018 & 01.10 & 184 & 2.5 & 2.7 & 11.0 & 5.1 & 81.2 & 197 & 4,2 \\
\hline 2017 & 10.10 & 193 & 2.2 & 4.2 & 22.0 & 2.5 & 71.3 & 159 & 4,9 \\
\hline 2016 & 29.09 & 230 & 3.2 & 1.9 & 16.9 & 4.8 & 76.4 & 216 & 6,1 \\
\hline 2015 & 26.08 & 208 & 3.4 & 1.6 & 16.8 & 3.5 & 78.1 & 157 & 6,7 \\
\hline 2014 & 30.09 & 216 & 2.4 & 3.2 & 15.5 & 5.1 & 88.2 & 159 & 4,7 \\
\hline 2013 & 03.09 & 150 & 2.0 & 2.9 & 9.3 & 5.1 & 82.7 & 179 & 4,7 \\
\hline 2012 & 28.08 & 304 & 3.0 & 2.5 & 13.2 & 4.1 & 80.2 & 149 & 5,6 \\
\hline 2011 & 16.09 & 342 & 3.4 & 2.2 & 19.6 & 2.9 & 75.3 & 161 & 6,9 \\
\hline 2010 & 14.09 & 246 & 3.2 & 3.0 & 15.4 & 4.6 & 77.0 & 159 & 4,8 \\
\hline average & 20.09 & 232 & 2.8 & 2.6 & 15.3 & 4.3 & 79.0 & 178 & 5,2 \\
\hline
\end{tabular}

The variety is used for the production of juices, dry and sparkling wines, fresh consumption. The end result of studying a variety is its technological evaluation. The obtained wine samples from the Donus grape variety had a volume fraction of ethyl alcohol from 9,5 to $11,8 \%$, titratable acids $4,3-7,6 \mathrm{~g} / \mathrm{dm}^{3}$, volatile acids not higher than 0,64 $\mathrm{g} / \mathrm{dm}^{3}$, the level of $17,4-20,8 \mathrm{~g} / \mathrm{dm}^{3}$, which corresponds to the requirements of regulations (table 7).

Table 7. Chemical and organoleptic characteristics of wine from the Donus grape variety, 20112019 (type of wine - dry white)

Years

\section{Chemical indicators of wine}




\begin{tabular}{|c|c|c|c|c|c|c|}
\hline & \multirow{2}{*}{$\begin{array}{l}\text { alcohol } \\
\text { \% vol. I }\end{array}$} & \multirow{2}{*}{$\begin{array}{c}\text { titratable } \\
\text { acids,g/dm }\end{array}$} & \multirow{2}{*}{$\begin{array}{c}\text { volatile } \\
\text { acids, } \\
\text { g/dm }\end{array}$} & \multirow{2}{*}{$\begin{array}{l}\text { extract, } \\
\mathrm{g} / \mathrm{dm}^{3}\end{array}$} & \multicolumn{2}{|c|}{$\mathrm{SO}_{2, \mathrm{~g} / \mathrm{dm}^{3}}$} \\
\hline & & & & & free & total \\
\hline 2019 & 10.8 & 7.6 & 0.54 & 20.8 & 19.6 & 102.6 \\
\hline 2018 & 11.8 & 5.5 & 0.48 & 19.7 & 16.2 & 152.9 \\
\hline 2017 & 9.5 & 4.5 & 0.44 & 17.5 & 14.8 & 126.8 \\
\hline 2016 & 11.2 & 5.8 & 0.64 & 18.9 & 11.8 & 104.9 \\
\hline 2015 & 10.4 & 4.3 & 0.64 & 19.4 & 15.3 & 105.6 \\
\hline 2014 & 11.7 & 4.7 & 0.42 & 18.6 & 14.8 & 186.4 \\
\hline 2013 & 11.2 & 4.5 & 0.48 & 17.9 & 12.8 & 98.6 \\
\hline 2012 & 10.1 & 7.6 & 0.64 & 17.8 & 16,8 & 168.8 \\
\hline 2011 & 11.3 & 6.4 & 0.54 & 18.8 & 17.6 & 128.8 \\
\hline 2010 & 11.8 & 4.9 & 0.57 & 17.4 & 18.6 & 116.9 \\
\hline average & 10.9 & 5.6 & 0.53 & 18.6 & 15.8 & 129.2 \\
\hline
\end{tabular}

Organoleptic evaluation is the main indicator of the quality of a wine. Wine from the Donus variety have an elegant appearance, pale straw color, delicate, graceful aroma with delicate nutmeg notesand a light, harmonious taste. The wine degustation evaluation in average 8.5 points on a ten-point rating scale.

\section{Conclusion}

Donus is a promising new variety of interspecific origin and is recommended for cultivation in the 6th region of industrial viticulture in Russia. High resistance to fungal diseases allows cultivating the variety with a minimum fungicidal load in the form of 2-3 preventive treatments, and the high frost-winter hardiness of the variety makes it possible to recommend the variety for cultivation in a non-covering crop even in the area of covering industrial viticulture.

\section{References}

1. M. Ferrer, G. Pereyra, J. Salvarrey, L. Arrillaga, M. Fourment, Vitis, 59(1), 41-46 (2020) doi: https://doi.org/10.5073/vitis.2020.59.41-46

2. Y. Gogorcena, M. Sánchez-Monfort, M. López-Vicente, Vitis (Special Issue), 58, 103110 (2019) doi: https://doi.org/10.5073/vitis.2019.58.special-issue

3. E. Zyprian, R. Eibach, O. Trapp, F. Schwander, R. Töpfer, Vitis, 57, 119-123 (2018) doi: https://doi.org/10.5073/vitis.2018.57.119-123

4. X. Wang, X. Xie, N. Chen, H. Wang, H. Li, Vitis, 57(1), 9-16 (2018) doi: https://doi.org/10.5073/vitis.2018.57.9-16

5. W. Marx, R. Haunschild, L. Bornmann, Vitis, 56(1), 35-43 (2017) doi: https://doi.org/10.5073/vitis.2017.56.35-43

6. F. Orlandi, T. Bonofiglio, F. Aguilera, M. Fornaciari, Vitis, 54(3),129-136 (2015) doi: https://doi.org/10.5073/vitis.2015.54.129-136

7. L. J. Welter, C. Tisch, A. Kortekamp, R. Töpfer, E. Zyprian, Vitis, 56(4), 181-188 (2017) doi: https://doi.org/10.5073/vitis.2017.56.181-188
8. J.
Karvonen,
Vitis,
53(4),
$175-180$ doi: https://doi.org/10.5073/vitis.2014.53.175-180 
9. C. F. Popescu, E. Maul, L. C. Dejeu, D. Dinu, R. N. Gheorghe, V. Laucou, T. Lacombe, D. Migliaro, M. CrespanVitis, 56(4), 173-180 (2017) doi: https://doi.org/10.5073/vitis.2017.56.173-180

10. E. Maletić, I. Pejić, J. KaroglanKontić, D. Zdunić, D. Preiner, S. Šimon, Ž., Vitis, (Special Issue) 54, 93-98 (2015) doi: https://doi.org/10.5073/vitis.2015.54.specialissue. 93-98

11. Young-Sik Park, Sun-Bai Bang, Jae-Yun Heo, Vitis, 56(4), 197-198 (2017) doi: https://doi.org/10.5073/vitis.2017.56.197-198

12. X.-P. Tang, J. Chen, X.-H. Ma, Z.-G. Dong, Qi-F. Zhao, X.-M. Li, W. Tan, M. Wang Vitis, 54(1), 47-48 (2015) doi: https://doi.org/10.5073/vitis.2015.54.47-48

13. M. Paolocci, M. Mugano, V. Alonso-Villaverde, K. Gindro, Vitis, 53(3), 155-161 (2014) doi: https://doi.org/10.5073/vitis.2014.53.155-161

14. K. C. Dahal, S. P. Bhattarai, A. Kicherer, D. R. Oag, K. B. Walsh, Vitis, 57(1), 27-34 (2018) doi: https://doi.org/10.5073/vitis.2018.57.27-34.

15. G. Merkouropoulos, S. Michailidou, A. Alifragkis, E. Zioziou, S. Koundouras, A. Argiriou, N. Nicolaou,

Vitis, (Special Issue) 54, 99-103 (2015) doi: https://doi.org/10.5073/vitis.2015.54.special-issue.99-103 